\title{
University Teachers' Perceptions of Screening Students' Communication Skills: A Case Study from Speech Pathology
}

\author{
Robyn Johnson \\ The University of Sydney, Australia \\ Alison Purcell \\ The University of Sydney, Australia \\ Emma Power \\ University of Technology Sydney, Australia \\ Kate Thomson \\ The University of Sydney, Australia
}

\begin{abstract}
Excellent communication and interpersonal skills are necessary for allied health professionals to provide effective care/treatment and underpin the practice-based competencies allied health students must develop. Communication skills of first year speech pathology (SP) students are screened at the major Australian metropolitan university where this study took place. Final year students screen their first year peers as part of their practice-based education experience. Although this identifies first year students with communication difficulties, the perceived value to university teachers (academics and practice educators) has not been investigated. This study described university staff perceptions of screening the communication skills of first year SP students. The qualitative, descriptive design included two focus groups. The dataset was analysed thematically. The analysis revealed the staff perception of value in screening communication skills to inform student support. Two sub-themes contributing to this perception were 'purpose of the screener' and 'content and administration of the screener'. Both staff groups strongly valued the screening process, stating that it is positive and useful. A similar screening process could identify first year students from a range of health fields with less skilled communication, who may require additional support to achieve competency.
\end{abstract}

Keywords: clinical skills development; communication screening; communication skills; health students; university teacher perceptions

${ }^{*}$ Corresponding Author: Robyn Johnson, The University of Sydney, Work Integrated Learning, Faculty of Health Sciences, Cumberland Campus, Lidcombe NSW 1825 Australia Email: robyn.johnson@sydney.edu.au

Journal URL: https://publications.coventry.ac.uk/index.php/pblh

Johnson, R., Purcell, A., Power, E., and Thomson, K. (2019) 'University teachers' perceptions of screening students' communication skills: A case study from speech pathology'. International Journal of Practice-based Learning in Health and Social Care, 7 (1), 32-46 https://doi.org/10.18552/ijpblhsc.v7i1.509

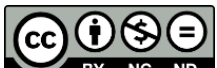

BY NC ND 2019 Robyn Johnson, Alison Purcell, Emma Power, and Kate Thomson. This Open Access article is distributed under the terms of the Creative Commons Attribution Attribution-Non-Commercial No Derivatives 4.0 International License (https://creativecommons.org/licenses/by-nc-nd/4.0/ ), which permits unrestricted non-commercial use, distribution, and reproduction in any medium, provided the original work is properly cited and is unaltered. 


\section{Introduction}

Good communication skills are essential for effective health professional practice in allied health, nursing, medicine, and pharmacy and are embedded in the professional standards (Brown et al. 2011, Hussainy, Styles and Duncan 2012, Physiotherapy Board of Australia \& Physiotherapy Board of New Zealand 2015, Rider, Hinrichs and Lown 2006, Speech Pathology Australia 2011). All programmes leading to accredited health professional qualifications aim to produce competent clinicians, and consequently, expect students to develop their communication skills during their degree. In speech pathology (SP), students must acquire excellent high-level communication and meta-communication skills in order to safely and effectively work with people whose communication is impaired during placements and as a speech-language pathologist after graduation. However, the underlying communication skills of school leavers are not typically assessed as part of admission to any health degree, including SP. At enrolment, these novice students' skills need to be proficient enough to enable them to develop the complex communication skills required for safe and effective practice as graduates.

Some disciplines, including physiotherapy (Parry and Brown 2009), medicine and nursing (Rider, Hinrichs, and Lown 2006, Wagner, Liston, and Miller 2011), and pharmacy (Hussainy et al. 2012, Stupans et al. 2010), have acknowledged the difficulties students have developing communication skills and have therefore introduced training for their students. Effective communication in health practice involves more than simply communicating fluently in the local language. The communication skills involved are complex: interpersonal communication such as conversing with a patient on their level or giving bad news (Rider, Hinrichs, and Lown 2006), and collaborative interprofessional communication skills (Taylor, Burley, and Nestel 2015). Developing these higher-level skills requires excellent underlying communication skills, including grammar, understanding of spoken or written language, pronunciation, body language and turn-taking. There is a lack of literature discussing which underlying communication skills are required to successfully develop the clinical competencies required for effective practice. A recent systematic review of communication assessments for university students and graduates (Chan, Purcell and Power 2016) indicated that most research to date has examined the clinical communication skills of predominantly medical and nursing students using standardised patients and Likert-based rating scales. They also note some less frequent use of single measures of language, including the Australian Tertiary English Test or the Woodcock Language Proficiency Test, to assess clinical communication, and list the detailed communication skills assessed. They report that assessment of clinical communication skills of allied health students has not been widely explored and there are few high quality published studies. None involved comprehensive or screening assessment of both speech and language skills administered by a speech-language pathologist. There is little published research into SP students' communication skills (Pederson [1988] is an exception). It is likely that university teachers have taken a more individualised developmental approach to fostering appropriate communication skills in their students (Shapiro, Ogletree, and Dale Brotherton 2002) because this is the 'bread and butter' work of the profession.

There is some emerging practice-based education literature in allied health fields addressing students' skills and predictors of successful clinical skills development, noting the need for more research to understand these fully (Johnson, Purcell, and Power 2013, Moore 2013). It is likely that a better understanding of students, including their communication skills (Johnson, Purcell, and Power 2013) and suitability to the profession (Moore 2013), could lead to learning support targeted to individual development needs. Johnson, Purcell, and Power (2013) identified a need for further research into early indicators of overall clinical competence in SP students, including undergraduate students, as existing literature focuses on post-graduate students (Forrest and Naremore 1998, Moore 2013, Shapiro, Ogletree, and Dale Brotherton 2002). Given the acknowledged importance of effective communication in developing clinical competence, it seems likely that communication may be one of these early indicators.

\section{Using a communication screener with SP students}

To help prepare first and final year undergraduate students for practice, a major Australian metropolitan university has, for two decades, screened the underlying communication skills of first year undergraduate SP students. University practice educators (PEs) firstly train final year SP students to screen first year students, then follow up those identified. It is not known whether screening the first year students is viewed positively, e.g. as providing an opportunity to support 
students, or negatively, e.g. stigmatising students who are identified. The screener was developed by the university to meet dual purposes: as a final year experience in screening adults and an early identification of first year students with communication difficulties (and in need of support). Its psychometric properties have not been explored or evaluated.

\section{Communication screener: Focus on skills required for practice}

The communication skills screened are: spoken language, speech sounds (pronunciation), fluency, voice, and phonological awareness (producing spoonerisms - e.g. toe nail becomes no tail). Working memory (digit recall) and hearing are also screened. These skills underpin successful SP practice and form the basis of the screener, as clinicians must use these skills to interact and converse with clients while observing and recording their communication skills in all of these areas (Speech Pathology Australia 2003). Consequently, students who are weaker in one or more of these skills may be at higher risk of failing a placement.

\section{Communication screener: Administration}

The communication screener takes around 30 minutes and is administered by final year SP students. Half of the screening appointments are in semester one and half in semester two because of the availability of these students. The students learn how to administer the screener as part of a one-day revision workshop on communication assessment at the start of a placement. The first year students are informed about the process early in each semester in lectures. The screening sessions are not supervised directly by an SP; the task of administering the screener is straightforward and the final year students neither know the pass/fail criteria for the screener nor provide feedback to first year students. The results are reviewed by an experienced SP PE from the on-campus clinic, who identifies the students with potential difficulties and refers them for further diagnostic assessment, e.g. to audiology for hearing assessments, to SP for voice assessments, or to a university PE for advice. Despite its use for many years, university staff perceptions of the screener have not been explored.

\section{Aim}

The present qualitative study aimed to discover the perceptions of the teaching staff (academics and PEs) in a university SP department about the use of a communication skills screener with students.

\section{Method}

This study is part of a wider project investigating the clinical skills development of student speechlanguage pathologists, approved by a university human ethics committee (HREC 2012/499). To minimise the ethical challenges associated with conducting qualitative research (Sanjari et al. 2014) the participants were required to sign an informed consent form prior to participating in the focus group interviews. Moreover, pseudonyms were assigned to each participant to ensure their anonymity and confidentiality.

The study took place within the SP department of a major Australian metropolitan university. The study utilised a qualitative and descriptive design.

\section{Participant selection and recruitment}

The participants were a purposive sample of two groups, academics $(n=5)$ and PEs $(n=4)$, recruited from the teaching staff in the SP department of a major metropolitan university. The potential participants, all female SPs, were selected based on their experience working with students in the university. An independent administrator emailed an invitation including information about the study to selected staff, of whom $90 \%$ agreed to participate. Although both group sizes were small, they represented $50 \%$ of each group of staff in the department who were not involved in this project and we determined that this would provide saturation in the data.

The academics had taught at the university for longer and had more experience as speech-language pathologists than the PEs. All academics and three PEs were graduates of this university. All academics and no PEs had PhDs, however, one PE had a research masters and two were PhD 
candidates. The academics were lecturers or full-time researchers and therefore not involved in the screening process or reviewing results. The PEs taught practice-based subjects in the on-campus clinic and were directly involved in advising first year students identified by the screener.

\section{Data collection method}

The first author facilitated two focus groups in the same small room on campus: one for PEs and one for academics. Focus groups were selected rather than interviews or surveys as participants were more likely to express their opinions during discussion (Tong, Sainsbury, and Craig 2007). The groups were 45 and 55 minutes in length, were audio and video recorded and contemporaneous notes made of key points. The audio recordings were transcribed, and the transcriptions analysed.

The facilitator asked the questions listed in Table 1, which were also printed on cards as a reminder for participants. The facilitator followed the same introductory script and order of questions in each group and moved to the next question when there were no further responses or discussion.

Table 1: Focus group prompt questions

1. Why do you think we screen the first year students?

2. What do you know about the way we screen the first year students?

3. How effective is the present process?

4. What is good about the present process?

5. How could the present process be improved?

\section{Reflexivity}

The first author has experience with the screener and is known to the participants, which may have had an effect on the discussion within the groups, particularly in the PE group who were very relaxed and open in their discussion. To minimise bias, the first author used a prepared script when facilitating to ensure that the same information and questions were given to each group of participants.

\section{Data management}

The recordings of both focus groups were transcribed; one by the first author, facilitating familiarisation with the data, and the other by a transcription service. To ensure accuracy, participants reviewed the transcript and made corrections (member checking).

\section{Data analysis}

Thematic analysis enabled identification of the themes and categories relevant to participants' perceptions of the screener. The process described by Rabiee (2004) was followed and is summarised in Figure 1. Stage 1 involved the first author reading and re-reading the transcripts and contemporaneous notes. In Stage 2, the use of focus groups meant that it was important to consider the interaction between participants. For this reason, conversational turns rather than lines were numbered before being coded according to common meanings and keywords. Where two concepts were represented in one turn, it was divided and the concepts coded separately. The codes were reviewed and labelled, before discussion, cross-checking and revision by the first three authors. In Stage 3, codes with similar content were grouped into categories and key participant quotations linked to the category labels. Stage 4 involved developing themes from the categories and Stage 5, identifying an overarching theme. A worked example is provided in Figure 2. 
Figure 1: Analysis process

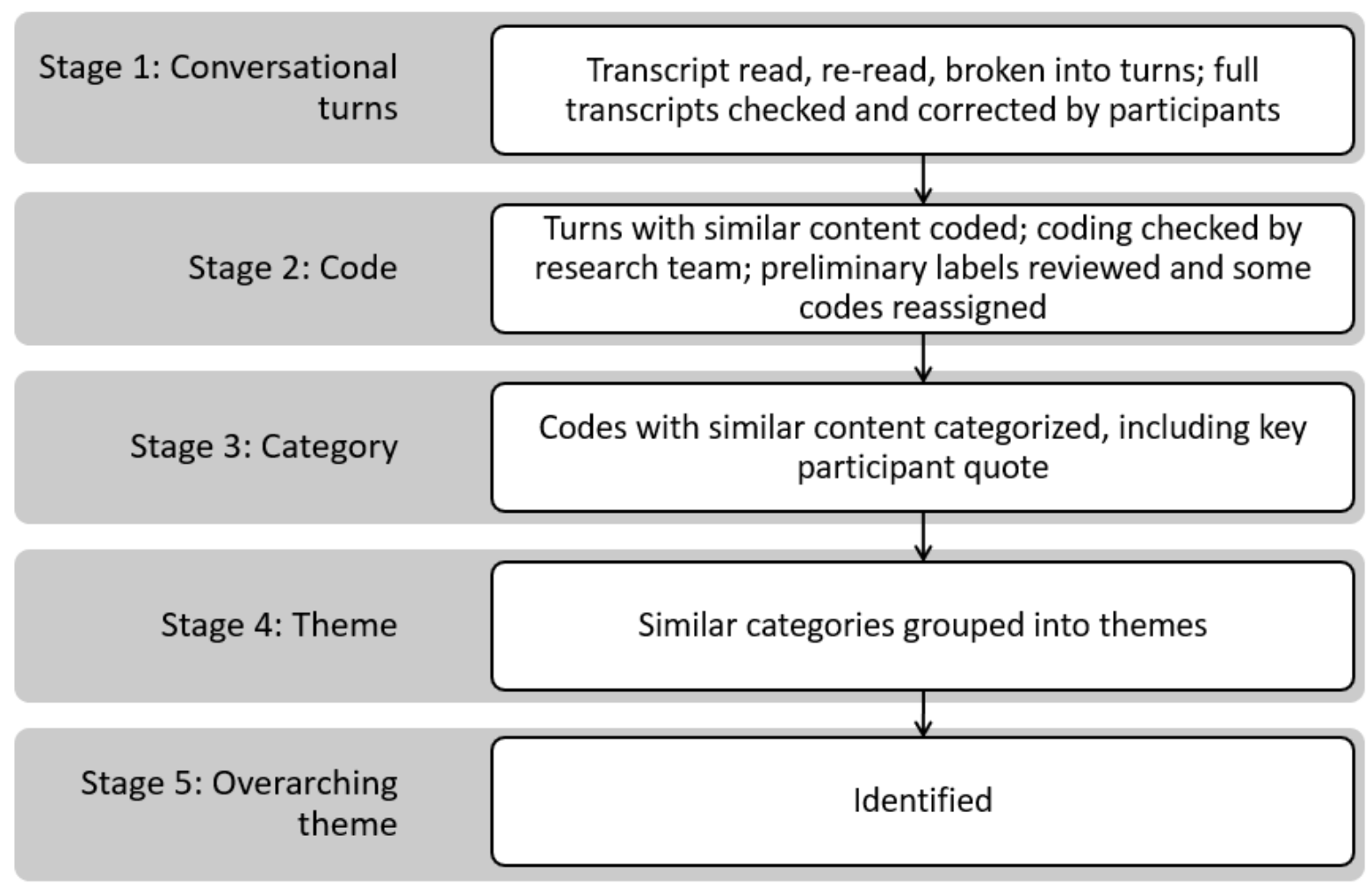

\section{Findings}

\section{Focus group interaction}

There was consistent agreement between the participants within each group and across the two groups, apart from when one participant made a comment to which no-one responded and when another made several comments with which all other participants immediately disagreed or noted to be off topic. A small number of codes were only discussed by one of the two groups (final year students' experience [PEs], mental health and timing of screener [academics]). Three of the PEs each took approximately twice as many conversational turns as the fourth.

Despite being more diverse in terms of experience, culture and education, the PEs shared perceptions and knowledge of the first year screener. They are involved in the management of the screener and its outcomes, so the high level of awareness and agreement is unsurprising. They work closely together as a team, whereas the academics work more independently. The PEs frequently finished each other's sentences, interrupted or spoke over each other, took many short turns and vigorously agreed with each other. The academics took longer turns and did not interrupt each other to the same extent. They posed many questions to each other, while the PEs offered answers and formulated solutions to problems or weaknesses raised during discussion, rather than simply identifying or commenting. The facilitator did not need to offer many of the planned prompts to facilitate the discussion in either group after asking each question, however offered clarification where necessary. On one occasion, a PE turned to the next question card as she wished to speed up the discussion. The academics asked for details of the content of the screen and the PEs did not. The academics also noted that the psychometric properties of the screener had not been investigated. 
Figure 2. Worked example of analysis

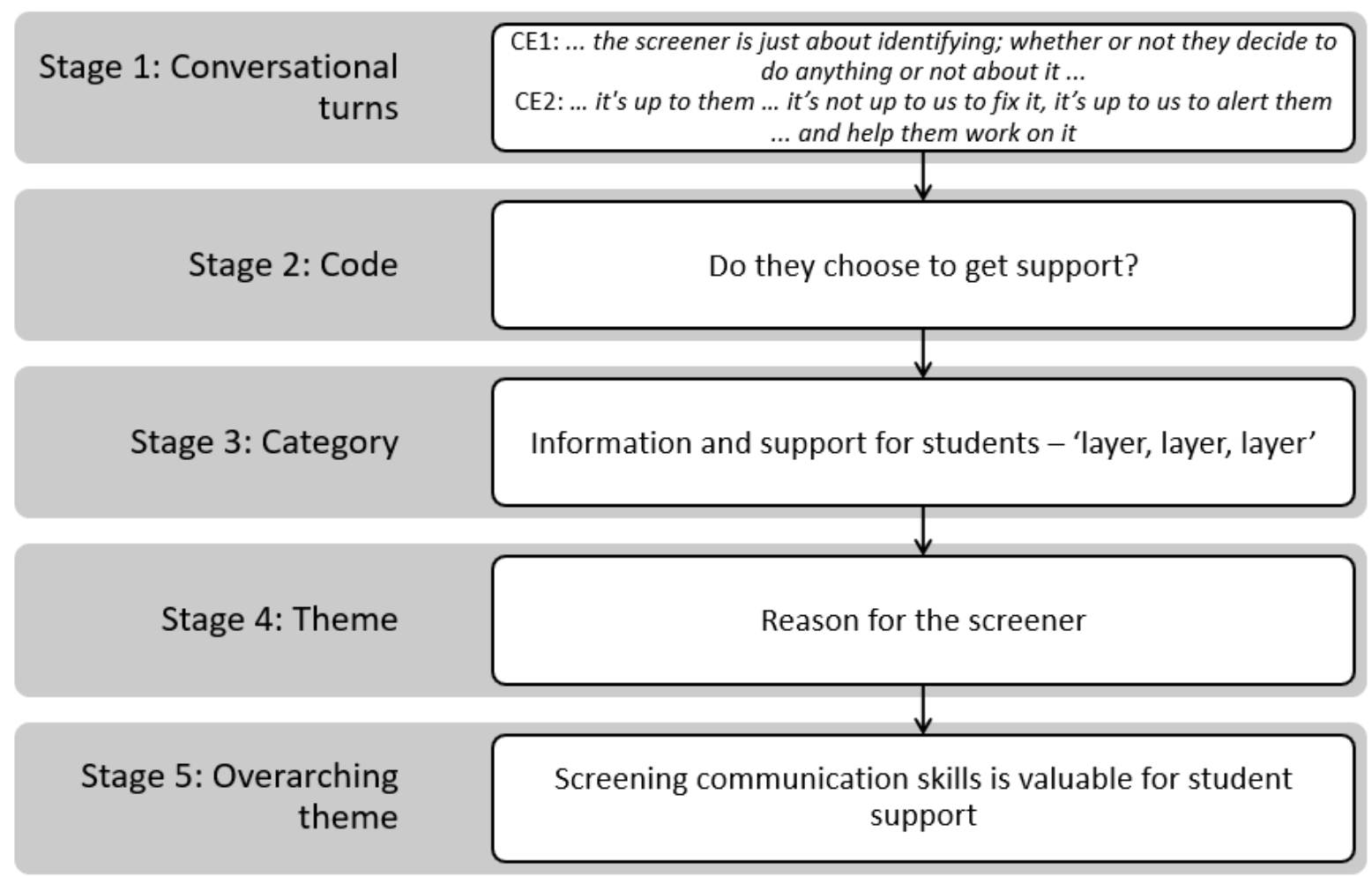

\section{Themes}

The main theme arising from the data was that screening students' communication skills is valuable in identifying a need for, and providing, targeted support. Both groups voiced opinions and strong agreement about this main theme. Tina (PE) said 'I think it's a useful thing. I think it's effective on the whole'. Sharon (academic) said 'I think it is a fantastic activity (be)cause you have to do everything so it is a real bringing together of all that you have learnt over the course and how important is it that you ... do that assessment with a first year who is starting something that you have just finished", to which other participants in the group agreed. Becky (PE) noted that the process helps 'the student who's being screened to raise their awareness of their own communication as a clinician, so that it's not always about other people but that their communication is of great importance'.

Two themes contributed to the overarching theme: 1 ) the reason for the screener i.e. why it is valuable and 2) content and administration of the screener. These are represented with their categories and codes in Table 2 and discussed below.

\section{Theme 1: Reason for the screener}

Both groups frequently discussed this theme, with participants offering both opinions and questions about the underlying reason behind the screener. The comments were grouped in three categories: the role of screener, information and support for students, and the role of universities. 
Table 2: Thematic overview: communication screening is valuable for student support

\begin{tabular}{|c|c|c|c|}
\hline Themes & Categories & Codes & Supporting evidence in literature \\
\hline \multirow[t]{3}{*}{$\begin{array}{l}\text { 1. Reason for } \\
\text { the screener }\end{array}$} & $\begin{array}{l}\text { 1.1 Role of } \\
\text { screener - 'What is } \\
\text { the purpose of the } \\
\text { thing?' }\end{array}$ & $\begin{array}{l}\text { - } \quad \text { What is the purpose of the thing?' } \\
\text { - } \quad \text { Identifies communication difficulties } \\
\text { - Students with previous difficulties } \\
\text { - } \quad \text { Pre-empts issues/identifies support } \\
\text { needs } \\
\text { - What do students think? }\end{array}$ & $\begin{array}{l}\text { - Marginal SP students have weaker communication skills than their } \\
\text { peers in the following areas (Shapiro et al. 2002): } \\
\circ \quad \text { oral and written communication } \\
\circ \quad \text { comprehension (may tend to memorise without real } \\
\quad \text { understanding) } \\
\circ \quad \text { knowledge of language content and structure } \\
\circ \quad \text { critical thinking and problem solving } \\
\circ \quad \text { synthesis and integration of ideas and translating theory to } \\
\quad \text { practice } \\
\circ \quad \text { interpersonal skills } \\
\end{array}$ \\
\hline & $\begin{array}{l}1.2 \text { Support for } \\
\text { students - 'Layer, } \\
\text { layer, layer' }\end{array}$ & $\begin{array}{l}\text { - } \quad \text { 'Layer, layer, layer' } \\
\text { - } \quad \text { Students from diverse backgrounds } \\
\text { - } \quad \text { Do they choose to get support? } \\
\text { - } \quad \text { Support offered } \\
\text { - } \quad \text { Future improvements }\end{array}$ & 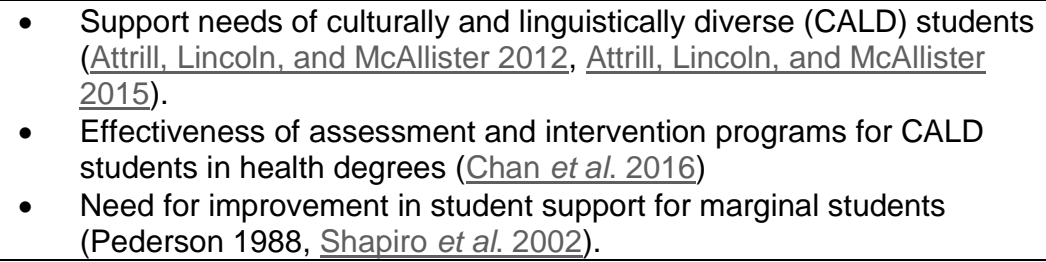 \\
\hline & $\begin{array}{l}\text { 1.3 Role of } \\
\text { university - 'We } \\
\text { serve as } \\
\text { gatekeepers for } \\
\text { the profession' }\end{array}$ & $\begin{array}{l}\text { - 'We serve as gatekeepers for the } \\
\text { - } \quad \text { Need for research: 'did it actually } \\
\text { help?' } \\
\text { - Imperfect internal team } \\
\text { communication }\end{array}$ & $\begin{array}{l}\text { - Need for research predicting which students will go on to have } \\
\text { difficulties. } \\
\text { - Issues facing faculty in managing marginal students, reflecting the } \\
\text { role of universities as 'gatekeepers' (Shapiro et al. 2002) }\end{array}$ \\
\hline \multirow[t]{2}{*}{$\begin{array}{l}\text { 2. Content and } \\
\text { administration } \\
\text { of the screener }\end{array}$} & $\begin{array}{l}\text { - } 2.1 \text { Process and } \\
\text { administration - } \\
\text { 'the first year } \\
\text { screening process' }\end{array}$ & $\begin{array}{ll}- & \text { Process } \\
\text { - } & \text { Timing } \\
\text { - } & \text { Student led } \\
\text { - } & \text { Future improvements }\end{array}$ & $\begin{array}{l}\text { - Timely support and intervention is important and improving the ability } \\
\text { to predict which students may become marginal is necessary. Given } \\
\text { the impact of poor communication skills, early identification is } \\
\text { advisable (Shapiro et al. 2002) }\end{array}$ \\
\hline & $\begin{array}{l}\text { 2.2 Content - } \\
\text { 'screener picks up } \\
\text { a whole lot of stuff' }\end{array}$ & $\begin{array}{ll}\text { - } & \text { Overall content } \\
\text { - } & \text { Writing } \\
\text { - } & \text { Mearing screening health issues } \\
\text { - } & \text { Does it screen anything useful for } \\
& \text { clinic? } \\
\text { - } & \text { Future improvements }\end{array}$ & $\begin{array}{l}\text { - For content of existing health student communication assessments } \\
\text { see } \underline{\text { Chan et al. (2016). }}\end{array}$ \\
\hline
\end{tabular}




\section{Category 1.1: The role of the screener - 'what is the purpose of the thing?':}

Both groups discussed their lack of clear understanding about both the present intended purpose and the original purpose. Some PEs recalled being screened themselves as students. There was general agreement however that the key present outcome of the screening is identifying communication difficulties in first year students that may lead to future learning problems (see Table 2), rather than the original purpose of providing an additional experience for final year students. Both groups agreed that difficulties with communication skills could lead to difficulties later on in placements, and indicated the screener could pre-empt future issues more related to practice-based learning than academic subjects. Both groups focused discussion on the first year students' skills, while questioning whether the screener actually assessed these, rather than final year student experience of administering the screener.

Both groups focussed on the effect of the screening process on the first year students, only briefly touching on the experience provided for the final year students and whether they are reliable clinicians for the screener. They also considered how first year students may view the screening process as a 'scary barrier' (Tina and Becky, PEs) rather than an early opportunity to identify areas where extra support could contribute to success in future practice-based subjects. The participants perceived that the screener is an important early step for students to understand the importance of their own skills in communication, i.e., 'raise their awareness of their own communication as a clinician' (Becky, PE).

\section{Category 1.2: Range of information and support available to the students - layer, layer, layer':}

Both groups agreed that the screener is an initial layer of information for students about their learning at university. This may be the first alert students have had about a communication issue. Both groups felt that conducting screening in first year is appropriate, as this allows adequate time to start offering support before placements begin. However, they noted that the students may still feel that placements are a long way in the future or fail to see the screener as related to their practice-based performance, as many do not follow through on recommendations promptly by seeking or accessing support. Sharon (academic) said 'they say "I have a problem" and I will say "so, have you noticed this before?" and they will say "Oh yes it got mentioned in first year", and they did nothing about it'. Vicky (PE) suggested that, for them, 'maybe it wasn't enough to flag action at the time, I don't know'.

The PEs are involved in the provision of feedback, recommendations, and support to first year students identified through the screening; this contributed to their detailed comments during the focus group. Different participants raised the importance of early identification several times; for example, discussing referring students for full hearing assessments or advising others to seek SP support.

Both groups discussed the impact of the screener on students from culturally and linguistically diverse (CALD) backgrounds, including both local and overseas students. The PEs discussed this at length, mentioning the range of views heard from international students, including from those who 'feel like they're punished from the start' (Tina) to others 'saying we don't pick them up early enough' (Becky). Becky went on to add, 'well I don't regard the first year screener as necessarily the be all and end all of that picking up process'. She then summed up the discussion by saying 'I think that yes, we need to do better by the international students, but that's not the purpose of this particular thing' to which the others agreed and the topic changed. The academics acknowledged the difficulties international students face, noting they '...come with their own set of difficulties: being away, being overseas, being a different culture for some, um, saving face...' (Louise), but talked more about students in general who may face communication difficulties. The PEs also discussed the wider issue of students with problems with 'English language and English grammar' (Vicky), leading to problems with report writing. 
Both groups felt that there were considerable improvements that could be made to the support offered. They discussed inequities of support, where PEs may take varying amounts of time to discuss an issue or one PE may have more expertise with the student's specific difficulty than others. Becky suggested that they 'make a little bit more standardised [murmurs of agreement] ... which means it would be a little bit more equitable [murmurs of agreement] in terms of what we tell students'. Some participants in both groups felt that additional areas, particularly high level language, should be added to the screener so that the students could become aware of the need to develop these skills further.

\section{Category 1.3: Role of universities - 'we serve as gatekeepers into the profession':}

The academics expressed more opinions than PEs in this area. They discussed their strong belief that speech-language pathologists need to be not just competent but excellent communicators. There was a high degree of agreement about the idea of being 'gatekeepers for the profession' (Julie, academic), including practice-based and academic competence and excellent communication skills. Julie reported views from speech-language pathologists such as 'I don't know how "they" would let that student through', indicating that the wider profession holds similar views to academics on the importance of excellent communication.

Both groups expressed concern over the lack of research into the effectiveness, reliability and validity of the screener in identifying communication difficulties in first year students, despite agreeing that this was its key purpose. They also agreed that excellent communication within the teaching team is pivotal in ensuring all are aware of the outcomes of the screening to enable coordinated support for identified students in both their practice-based and academic subjects.

\section{Theme 2: Content and administration of the screener}

Both groups also widely discussed the operational issues of the screener. The comments were grouped in two categories: 1) the process of administering the screener and 2) the content of the screener. The PEs had particularly strong views and were very familiar with the operation of the screener, while the academics were less familiar with the process, arrangements and outcomes.

\section{Category 2.1: Process and arrangements for the screener - 'the first year screening process':}

The PEs provided much detail about the actual process including how the first and final year students sign up to participate in the screener, where it occurs, where the students meet and whether either group of students has knowledge of the results as they participate in the screener. The academics noted that screening is not voluntary and asked about the timing in the year, noting that semester one of first year involves a very big learning curve for students and questioned the timeliness. However, the majority indicated that the fact that it is completed - and completed early - is good. The PEs did not discuss the timing of the screening.

Both groups discussed the student-led nature of the screener and agreed that there were advantages to 'peers assessing peers' (Susan, academic), with the PEs particularly satisfied that this was the case. However, both groups also discussed the potential difficulties with this, as the success of each screener depends on the skill level of the final year student administering the screener and the skill levels vary across students. Both groups acknowledged that the varying skill levels of the students are a weakness of the process, with an academic commenting that an improvement would be for the screening to be done by a qualified speech- 
language pathologist. Others felt that the process would be improved by further standardisation such as conducting it in only one semester.

\section{Category 2.2: Content of the screener - 'screener picks up a whole lot of stuff':}

Again, the PEs were very knowledgeable about the overall content. The academics were not familiar with the content and referred to copies of the screener throughout the focus group. Both groups noted that the screener is more likely to pick up 'obvious' grammar, speech, voice, fluency and hearing issues than to identify high-level language or pragmatic difficulties. The academics noted 'no synthesis or integration' (Julie) is screened. The PEs felt that the hearing screening was 'probably one of the more concrete and valuable parts of it' (Lisa), as did the academics. Both groups queried whether the screener is related closely enough to the skills required in the clinic. Both also wondered about the students' perceptions of the screener and its relationship to their experiences in clinic.

Only the academics discussed the issue of the students' mental health and wondered if this could also become part of the screener. Both groups made suggestions for improvement, including a reading comprehension or written task. Both also felt that screening for high-level language skills would also be useful and here participants were more specific.

\section{Discussion}

This study aimed to investigate the perceptions of university teachers (PEs and academics) on screening the communication skills of first year SP students. Both groups perceived the screening process to be worthwhile and effective, both as a final year student task and as an early identifier of first year students needing support. Both groups valued the detailed information gained about the students' specific communication skills, as this enabled them to plan tailored and specific advice and support. Participants saw the screener as an equitable way to start a conversation around support with potentially at-risk students, as screening the whole cohort does not single out any specific group, reflecting the need for a level playing field for students of all ability levels (Moriña Díez, López, and Molina 2015). In addition, the findings provide considerations for developing a more detailed communication screener for use with SP and other health students. There needs to be a clear purpose for the screening that must be understood by and communicated to the students and the university staff. Although both groups noted limitations of the screener for SP students (e.g. regarding high level language or pragmatics), these may not be as relevant for students in other health disciplines as requirements for effective professional practice vary. Universities could use these findings to determine which communication skills should be screened for each discipline, and then to identify and support all health students, including exploring incentives and barriers around students accessing support.

Governments worldwide are committed to increasing the numbers of students from different social and cultural backgrounds (Gale and Tranter 2011, Greenbank 2006). Universities have responded with support structures to enable this wider range of students to succeed at their studies. Student learning is enhanced through facilitating the development of insight into their own learning skills, and screening the communication skills of first year students is one way to do this. The participants noted that the screener allows students to start the process of learning more about themselves in general, their skills, and in some cases, beginning to understand that achieving competency requires more work than they had anticipated. They perceive that early identification facilitates relevant and timely support being offered to students with potential issues, but were concerned that not all students act on the recommendations to seek support 
promptly. Comments from both groups indicated a tension between a duty of care for the students and the students' autonomy as adult learners.

Both groups of participants perceive that there are students, both local (with or without CALD backgrounds) and international who have issues with communication. Participants all recognised the difficulties faced by these students to achieve the high level of communication competence required to graduate as an entry level speech-language pathologist. The PEs discussed the additional challenges some international students may encounter on placement with using high-level English communication skills while simultaneously developing their other professional practice-based skills. This discussion among the participants supports the findings of Attrill, Lincoln, and McAllister (2012), who reported that practice-based education coordinators from ten Australian and New Zealand Universities perceive that international students have greater difficulties in acquiring competence in communication, among other areas. Both groups expressed concern about the success or failure of struggling students, whether they are local, international, English speaking or CALD, in both practice-based and academic units. This view of university staff contrasts with the findings of Attrill, Lincoln, and McAllister (2012, 2016) who reported that practice education coordinators believe that the "CALD status of students has a greater influence on placement performance than whether they are domestic or international students" (2012: 269).

To assist health students succeed with their academic and practice-based studies, a deeper understanding of how students benefit from being identified as having a communication or hearing problem is warranted. Nemeth and McAllister (2010) described the lack of insight some SP students have into the difficulties that contributed to failing a placement, noting these students may be angry at their failure and are not ready to learn from the experience. The findings of this study appear to reflect this, as both groups expressed their perceptions that some students do not follow any of the recommendations provided. It is likely that these novice students do not fully understand that any limitation in their communication skills could make attaining SP practice-based competence more challenging. Additionally, their poorer communication skills may also be contributing to this lack of seeking support or following advice, as studies have indicated that students with lower levels of skill often lack awareness about their abilities (Ehrlinger et al. 2008). It is possible that SP students with weaker skills also lack insight into their competency. Further research into this area is warranted, as, if this is the case, students who do not perceive that their skills need further development may be difficult to engage in support and early intervention following the screener and other opportunities for support. The PEs discussed ways to improve the support offered to the students, such as offering advice in a more standardised manner across the team, including developing support pathways and written recommendations. As previously mentioned, some disciplines have developed more generic communication training modules for their students (Parry and Brown 2009, Rider, Hinrichs, and Lown 2006, Wagner, Liston, and Miller 2011), focussing on aspects of clinical interviewing rather than the underlying communicatin skills of the students. Further research into the effectiveness of existing and proposed strategies to support high-risk students is required.

\section{Recommendations}

This study found that university teachers value a communication screening process as a starting point for discussion with students about further developing their skills prior to their placements. A clear, standardized support package for identified students is desirable, including strategies and requirements for students to implement these. The results should inform development of processes to identify and support health students with weak clinical communication skills. 
Future research could explore the psychometric properties of the screener and whether it serves to identify the students who are at risk of failing placements. If it was found to be of this use, the screener could also form the basis of a screener for other universities' SP students, or students from other health disciplines. Further, perceptions of teachers at other universities about the desirability of screening the communication skills of students could be explored. However, the themes discussed in this study reflect those described in the literature, including both the perceptions of university teachers about student skills and their desire to develop appropriate strategies to support students (Attrill, Lincoln, and McAllister 2012, Attrill, Lincoln, and McAllister 2016, Chan, Purcell and Power 2016, Parry and Brown 2009, Rider, Hinrichs and Lown 2006, Shapiro, Ogletree, and Dale Brotherton 2002, Stupans et al. 2010, Wagner, Liston, and Miller 2011).

\section{Limitations}

We investigated perceptions of staff in only one university and could not find published evidence that other universities screen the communication skills of their SP students. The psychometric properties of the screener have not been explored recently, and as the focus group participants were aware of this, they were not discussed during the focus groups.

\section{Conclusion}

This study has shown that university teachers (academics and PEs) at a major metropolitan university in Australia perceive that screening the communication skills of SP students early in their degree has a range of benefits. Some participants saw the process as a capstone experience for final year students, bringing together the academic and practice-based skills they have learnt over the degree. Others focussed more on the benefits to the first year students, particularly in developing an awareness of the importance of communication skills in becoming competent speech-language pathologists, and the early identification of students who may benefit from tailored support. It is likely that health students in a range of disciplines would also benefit from a similar screening and support process to develop their clinical communication skills.

\section{Declaration of interest}

The authors report no conflicts of interest. The authors alone are responsible for the content and writing of the article.

\section{Acknowledgements}

The authors would like to thank the participants who generously shared their time and experiences. 


\section{References}

Attrill, S., Lincoln, M., and McAllister, S. (2012) 'Student diversity and implications for clinical competency development amongst domestic and international speech-language pathology students'. International Journal of Speech-Language Pathology, 14 (3), 260270 https://doi.org/10.3109/17549507.2011.652172

Attrill, S., Lincoln, M., and McAllister, S. (2015) 'International students in speech-language pathology clinical education placements: Perceptions of experience and competency development'. International Journal of Speech-Language Pathology, 17 (3), 314-324 https://doi.org/10.3109/17549507.2015.1016109

Attrill, S., Lincoln, M., and McAllister, S. (2016) 'Supervising international students in clinical placements: Perceptions of experiences and factors influencing competency development'. BMC Medical Education [online] 16, 180 https://doi.org/10.1186/s12909016-0702-5 [31 January 2018]

Brown, T., Williams, B., Boyle, M., Molloy, A., McKenna, L., Palermo, C., Molloy, L., and Lewis, B. (2011) 'Communication styles of undergraduate health students'. Nurse Education Today 31 (4), 317-322 https://doi.org/10.1016/i.nedt.2010.06.006

Chan, A., Purcell, A., and Power, E. (2016) 'A systematic review of assessment and intervention strategies for effective clinical communication in culturally and linguistically diverse students'. Medical Education, 50 (9), 898-911. available from https://doi.org/10.1111/medu.13117 [31 January 2018]

Ehrlinger, J., Johnson, K., Banner, M., Dunning, D., and Kruger, J. (2008) 'Why the unskilled are unaware: Further explorations of (absent) self-insight among the incompetent'. Organizational Behavior and Human Decision Processes, 105 (1), 98-121 https://doi.org/10.1016/i.obhdp.2007.05.002

Forrest, K. and Naremore, R.C. (1998) 'Analysis of criteria for graduate admissions in speechlanguage pathology: Predictive utility of application materials'. American Journal of Speech-Language Pathology, (7) 4, 57-61 https://doi.org/10.1044/1058-0360.0704.57

Gale, T. and Tranter, D. (2011) 'Social justice in Australian higher education policy: An historical and conceptual account of student participation'. Critical Studies in Education, 52 (1), 29-46 https://doi.org/10.1080/17508487.2011.536511

Greenbank, P. (2006) 'The evolution of government policy on widening participation'. Higher Education Quarterly, 60 (2), 141-166 https://doi.org/10.1111/i.1468-2273.2006.00314.x

Hussainy, S.Y., Styles, K., and Duncan, G. (2012) 'A virtual practice environment to develop communication skills in pharmacy students'. American Journal of Pharmaceutical Education [online] 76 (10), 202. available from https://doi.org/10.5688/ajpe7610202 [31 January 2018]

Johnson, R., Purcell, A., and Power, E. (2013) 'Developing speech pathology clinical competency: Are there predictors for success?' Journal of Clinical Practice in SpeechLanguage Pathology, 15 (2), 60-64. 
Moore, M.L. (2013) Predictive Admission Criteria in Graduate Programs in Speech-Language Pathology. [online] doctoral dissertation. Western Kentucky University available from http://digitalcommons.wku.edu/diss/52 [31 January 2018]

Moriña Díez, A., López, R.G., and Molina, V.M. (2015) 'Students with disabilities in higher education: A biographical-narrative approach to the role of lecturers'. Higher Education Research \& Development, 34 (1), 147-159 https://doi.org/10.1080/07294360.2014.934329

Nemeth, E. and McAllister, L. (2010) 'Learning from failure'. in Clinical and Fieldwork Placement in the Health Professions. ed. by Stagnitti, K., Shoo, A., and Welch, D. South Melbourne, Australia: Oxford University Press, 218-230

Parry, R.H. and Brown, K. (2009) 'Teaching and learning communication skills in physiotherapy: What is done and how should it be done?'. Physiotherapy, 95 (4), 294-301 https://doi.org/10.1016/i.physio.2009.05.003

Pederson, H.R. (1988) 'Students with communication difficulties in master level speechlanguage pathology programs: Prevalence, academic and clinical progress, and related program policies'. Theses, Dissertations, Professional Papers, University of Montana [on-line] available from https://scholarworks.umt.edu/etd/7189/ [31 January 2018]

Physiotherapy Board of Australia \& Physiotherapy Board of New Zealand (2015) Physiotherapy Practice Thresholds in Australia and Aotearoa New Zealand [on-line] available from https://physiocouncil.com.au/wp-content/uploads/2017/10/Physiotherapy-BoardPhysiotherapy-practice-thresholds-in-Australia-and-Aotearoa-New-Zealand.pdf [31 January 2018]

Rabiee, F. (2004) 'Focus-group interview and data analysis'. Proceedings of the Nutrition Society, 63 (4), 655-660 https://doi.org/10.1079/PNS2004399

Rider, E.A., Hinrichs, M.M., and Lown, B.A. (2006) 'A model for communication skills assessment across the undergraduate curriculum'. Medical Teacher, 28 (5), e127-e134 https://doi.org/10.1080/01421590600726540

Sanjari, M., Bahramnezhad, F., Fomani, F. K., Shoghi, M., and Cheraghi, M. A. 2014. 'Ethical challenges of researchers in qualitative studies: The necessity to develop a specific guideline'. Journal of Medical Ethics and History of Medicine [online] 7 available from https://www.ncbi.nlm.nih.gov/pmc/articles/Pmc4263394/ [31 January 2018]

Shapiro, D.A., Ogletree, B.T., and Dale Brotherton, W. (2002) 'Graduate students with marginal abilities in communication sciences and disorders: Prevalence, profiles, and solutions'. Journal of Communication Disorders, (35) 5, 421-451 https://doi.org/10.1016/S00219924(02)00093-X

Speech Pathology Australia (2003) Scope of Practice. [online] available from http://www.speechpathologyaustralia.org.au/referring-professionals/scope-of-practice [20 September 16]

Speech Pathology Australia (2011) Competency-based Occupational Standards (CBOS) for Speech Pathologists: Entry Level. [online] available from 
http://www.speechpathologyaustralia.org.au/all-latest-news/1037-cbos-2011 [20 September 16]

Stupans, I., Owen, S., Ryan, G., Woulfe, J., and McKauge, L. (2010) 'Scaffolding patient counselling skills in Australian university pharmacy programs'. Asia-Pacific Journal of Cooperative Education, (11) 2, 29-37

Taylor, J., Burley, M., and Nestel, D. (2015) 'Integrating interprofessional education and simulation in community health: Evaluation of a practice-based student clinic'. International Journal of Practice-based Learning in Health and Social Care, 3 (1), 94107 https://doi.org/10.18552/ijpblhsc.v3i1.210

Tong, A., Sainsbury, P., and Craig, J. (2007) 'Consolidated criteria for reporting qualitative research (COREQ): A 32-item checklist for interviews and focus groups'. International Journal for Quality in Health Care, 19 (6), 349-357 https://doi.org/10.1093/intahc/mzm042

Wagner, J., Liston, B., and Miller, J. (2011) 'Developing interprofessional communication skills'. Teaching and Learning in Nursing, 6 (3), 97-101 https://doi.org/10.1016/j.teln.2010.12.003 